\title{
Qualitative Assessment of Experience on Urban Forest Therapy Program for Preventing Dementia of the Elderly Living Alone in Low-Income Class
}

\author{
Hyun Jin Lee ${ }^{1}$ and Sung Ae Son ${ }^{2 *}$ \\ ${ }^{1}$ Interdisciplinary Program in Landscape Architecture, Seoul National University, Seoul 08826, Korea \\ ${ }^{2}$ Department of Forest Therapy, Graduate School of Chungbuk National University, Cheongju 28644, Korea
}

\begin{abstract}
Previous studies have shown that forest therapy program can help prevent dementia. However, few studies have focused on low-income elderly people living alone. The current study examined the meanings that the elderly living alone receiving medical care assigned to the urban forest therapy program, as a way to understand the pathways that nature-based intervention affect preventing dementia. Twenty-one participants were recruited and they participated in a five-week urban forest therapy program. Semi-structured interviews were carried out with 21 participants who experienced the urban forest therapy program, and analyzed qualitative data using thematic analysis. Results showed that all themes identified were related to connectedness with oneself, neighbors and nature. Awarenesses of change were consisted of positive and negative themes. The themes of positive awareness were improvements of mental and emotional condition, feelings of isolation and loneliness, and health-related lifestyle. The negative themes were terminations of short-term programs and inconvenient access to the urban forest. Based on these data, we suggest an urban green welfare framework for future research and interventions for preventing dementia of underprivileged elderly group.
\end{abstract}

Keywords: mental health, thematic analysis, underprivileged older people, urban forest healing

\section{Introduction}

The number of people with dementia is soaring due to the rapid aging of societies across the world, which is leading to a huge increase in social costs (Wimo et al., 2017). The World Health Organization (WHO) has predicted that the number of dementia patients around the world will more than triple to 152 million in 2025 due to the aging of society. The organization recognized dementia as a serious social problem, and announced the Global Action Plan on the Public Health Response to Dementia in May 2017. In South Korea, the prevalence rate of dementia (23.7\%, from 610,000 patients in 2014 to 1.01 million patients in 2024) is expected to increase more rapidly than the rate of the growth of the elderly population (15.8\%, from 6.39 million in 2014 to 1.01 million in 2024) (MHW, 2015).

The forest therapy program in this study was run by Healing Forest Cooperative with the support of Korea Forest Service, Korea Forest Welfare Institute, and Lottery Fund (Green Fund).

Received: October 30, 2018, Revised: November 5, 2018, Accepted: November 21, 2018

First author: Hyun Jin Lee, E-mail: hlhl411@gmail.com, ORCID: 0000-0001-5061-2716

*Corresponding author: Sung Ae Son, E-mail: adept13@naver.com, ORCID: 0000-0003-0993-2042 
Since a drug for dementia has not been yet developed, once the disease develops, the slow process of deterioration over a long period of time is accompanied by many burdens and much suffering. In particular, in the case of the elderly living alone on low income, they could be more vulnerable to the onset of dementia due to the lack of personal and social support and networks (Ennis et al., 2014). In South Korea, the number of elderly people living alone is increasing along with the increase of the elderly population. The number of elderly living alone was 1.44 million in 2016 and it is expected to be 3.43 million in 2035 (KOSIS, 2016). Therefore, it is the best approach to reduce the risk factors associated with the onset of dementia or delay the onset of the disease through healthy lifestyles (Barnard et al., 2014). In addition, it should be recognized that dementia is no longer a personal problem, but a social problem. Accordingly, there is an urgent need to develop prevention and management programs for high risk groups by strengthening preventive intervention.

Forest therapy or forest healing is one of the nature-based therapy methods that can improve physical and mental health by using various environmental factors such as landscapes, sounds, phytoncides, negative ions, and lights (Yu et al., 2017). The risk factors of dementia include psychological and physiological factors (Deckers et al., 2015), and the forest therapy program is effective in reducing anxiety, depression, and stress which are known as psychological dementia risk factors (Yu et al., 2017; Vujcic et al., 2017). Furthermore, it was reported that the therapy improved the autonomic nervous system responses and cognitive functions of elderly patients with dementia (Bratman, 2015; Kim, 2017), and also assisted in improving chronic diseases such as stabilizing heart rate variability (HRV) and pulse rate (Yu et al., 2017), decreasing blood concentration of stress hormones (Jia et al., 2016), lowering blood pressure of patients with high blood pressure (Mao et al., 2012; Song et al., 2017), and lowering blood glucose levels of patients with diabetes (Song et al. 2017). In this regard, it is expected that intervention utilizing the forest therapy program could be effective in preventing dementia and bring about other positive effects such as reducing social costs.

However, even though it is a fact that the elderly aged over 75 are classified as a high risk group who are particularly vulnerable to dementia (MHW, 2015), there are few studies on nature-based programs for the elderly living alone on low income. In order to expand the forest therapy program as part of a green welfare scheme to deal with the aging of society, it is necessary to understand to how vulnerable social groups are aware of the urban forest and therapy program, and what are the obstacle factors and diffusion factors in promoting them.

This study aimed to examine how the elderly living alone on low income recognized the urban forest therapy program in their daily life and what changes they experienced through this program. The study also sought green welfare measures for the elderly living alone on low income from the findings.

\section{Research Methods}

\section{Research design}

To comprehensively understand regarding awareness of the urban forest therapy program to prevent dementia targeted at the elderly living alone who are medical aid beneficiaries and the changes brought about by such a program, this study conducted a qualitative research that analyzed data by using a thematic analysis method which is a data analysis method that explores contexts and situations. Qualitative research is an alternative approach to positivist quantitative research, and is also a phenomenological type and method that approaches the phenomenon 'as it is' or 'from its original standpoint' as much as possible (Tong et al., 2007). Since important information such as the values of the research participants or their past experiences cannot be obtained through observation or scale, the analysis method collects data through interviews, and categorizes and classifies transcribed data after recording the interviews with the interviewees' consent, and identifies important themes or meanings through this process (Tong et al., 2007). Theme analysis (Braun and Clarke, 2006) derives patterns or themes related to the experienced meaning of participants. This 
method is effective in constructing the meanings and experiences of individuals derived from social and environmental contexts (Braun and Clarke, 2006), and it is especially important to understand the experiences of vulnerable groups with low social status or who lack social support in social and cultural contexts (Mama et al., 2016). Therefore, the theme analysis method is an appropriate research method for exploring participants' experiences and the meanings they place on things. The interview format followed a format to gain a detailed understanding of participants' experiences, recognition, beliefs, values, and behaviors (Ponterotto, 2002), and it aimed to comprehend relatively unknown concepts including the personal meaning of the urban forest for the elderly living alone.

\section{Forest therapy program}

The urban therapy program for preventing dementia was conducted from September 10 to October 17, 2018 except for holidays, from 10 a.m. to 1 p.m. once a week, with five sessions in total. The places were nature study trails and therapeutic forest trails located in the urban forest of $\mathrm{N}$-gu in Seoul. The main activities of the program were divided as follows: 'Dementia prevention exercise and forest walking' in order to manage risk factors for depression and dementia (Lee, 2009; Kim and Ahn, 2015), 'Five senses meditation' in order to induce cognitive stimulation and relieve emotions by reducing unnecessary distractions and concentrating on their own body and five senses (Yoo, 2010; Lee and Shin, 2015), and 'Traditional therapeutic play' to work effectively on relieving emotions and increasing physical residual function capacity (Seo, 2007) by re-experiencing the emotions and memories of their childhood through traditional play activities using natural objects (Table 1). The progression per session consisted of introduction(20 30 minutes, dementia prevention exercise and forest walking, five senses meditation, etc.), development (120 minutes. therapeutic play activities, lunch), and closing (20 30 minutes, feedback, assigning task) respectively.

\section{Research participants and ethical considerations}

Participants for this study were the elderly living alone in single households who were medical aid recipients over 65 years old, who didn't have problems related to physical activities and who participated in the 'Urban forest therapy program for preventing dementia' conducted in an urban forest in Seoul. They were recruited from residents of A-dong and B-dong in N-gu that are areas not originally related to the program, and consisted of people who were willing to participate voluntarily after receiving an adequate explanation regarding the purpose and methodology of the study. The total number of participants were 21 people, the group being composed of 8 men (average age: $73.7 \pm 4.3$ ) and 13 women (average age: $74.6 \pm 7.0$ ). Except for two participants, all of them had mild chronic diseases such as backache, high blood pressure, and diabetes. Before collecting the data, the researchers clearly identified themselves, explained the purpose and process of the study, and also explained that the anonymity of the participants would be guaranteed and the collected data

Table 1. Activity details of forest therapy program for preventing dementia

$\begin{aligned} & \text { Contents } \\ & \text { Warming up } \\ & \begin{array}{l}\text { Forest walking } \\ \text { Five senses meditation } \\ \text { Traditional therapeutic play } \\ \text { Feedback \& Assignment }\end{array} \\ & \text { Walking slowly while listening to the sound of the forest, looking at the trees and feeling the wind } \\ & \text { Focusing on listening to, looking at and feeling the nature, deep breathing }\end{aligned}$


would be used for research only. In addition, participants signed the study agreement after receiving an explanation that the data would be discarded at the end of the study and that they had the right to refuse continuing with their participation during the study.

\section{Data collection and analysis method}

Data collection was conducted at the end of the therapy program, October 16 (13 participants from A-dong) and October 17, 2018 (8 participants from B-dong) in the urban forest by interviewing the focus groups. The focus-group interview is a group interview wherein purposive participants to a specific topic get together and have a focused discussion in a narrative way (Rabiee, 2004). It is a useful method to collect the participants' thoughts and feelings on a new theme because the method has a synergy effect of interaction which makes them realize unrecognized things after listening to the remarks of others (Morse, 1994). Furthermore, the advantage of this method is that it is easier to obtain information from a group interview where there is a sense of kinship rather than a face-to-face interview with a researcher when there is a difference in social status between participants and researchers (Gubrium et al., 2012). The researchers provided the participants with the research method and content again just before the interview, and they explained the interviews would be recorded. The researchers also informed them that the research content would be used for research only and the content would be discarded at the end of the study.

The interviews were conducted for one and a half hour, respectively. A semi-structured type format was used based on questions, and the main questions selected as a result of discussion among researchers were as follows: (1) What is the meaning or significance of participating in the urban forest therapy program? (2) How did you come to be aware of urban forests and the therapy program? and (3) How does the urban forest affect an individual's health and well-being either positively or negatively?

All the interviews were transcribed by the researchers and the manuscript was entered into NVivo version 12, qualitative analysis software, after assigning a number (e.g. P1) to each participant. In the input data, meaningful words, sentences, and paragraphs were open-coded first, and then were grouped and classified in similar sentences and paragraphs. The classified sentences and paragraphs were categorized and given labels based on their category (Hsieh and Shannon, 2005). The researchers concluded the final result through discussion for adding and revising categories by continuing to compare different situations while reaffirming the analysis process of extracting concepts and labelling the categories.

\section{Reliability and validity}

The study was conducted based on the evaluation standard of qualitative research(Guba and Lincoln, 1989) in order to secure reliability and validity. To secure the facticity of the data, the research assistant summarized the discussion after the interview with the focus group and received participants' consent, and this confirmed that the contents of the interviews were faithfully and accurately recorded and summarized. The applicability of the study was secured by sending our finally analysed study result to a forest therapy expert and a program operator and asking them to check the study content.

\section{Results and Discussion}

Participants agreed that experiencing the program was good and they positively responded to the forest welfare services. In addition, they attached special significance to the therapy program as it enabled them to have a chance to learn about healthy lifestyles by experiencing dementia prevention exercises and activities, and because it also can pave the way for them visit forests with neighbors with whom better relations are established. On the other hand, they mentioned in the 
discussion that the number of the elderly who wanted to participate in the program had increased, but that there were many obstacles to participating in the program such as a lack of publicity about the program. They also suggested measures for activating the program.

\section{Awareness of urban forest and forest therapy program}

The elderly living alone who experience isolation and loneliness recognized and appreciated that all the themes associated with the urban forest and the therapy program participation afforded them opportunities to establish relations and have a sense of belonging. The characteristics of the urban forest and the therapy program experiences can be categorized into three themes based on the agreement and decision of the researchers: 'Connectedness with self through immersion and fulfillment', 'Connectedness with self and neighbors', and 'Connectedness with self and nature'. They were based on the representative quotations presented below:

\section{Connectedness with self through immersion and fulfillment}

The participants regarded the urban forest as a safe space for leisure activities and demonstrated an awareness that the forest could serve as a motivation to naturally they can be immersed in themselves. For example, when discussing the importance of the urban forest in daily life, they stated the following: "This is a good place to spend time. I have different thoughts whenever I come here, and I can escape such thoughts here." "I took a walk here by taking a bus alone when I didn't have a program. I didn't think I would come to a mountain before, but now I'm pleased to have a place to go in my town."

Many participants recognized the urban forest as a place where they can recharge their energy and improve their physical and mental health, and discussed how people can spend their time alone in the forest and immerse themselves in their favorite activities to feel joy. "I like quiet things, so when I listen to the birds, I feel gratitude to all the things and feel alive." "I see camellia trees in the mountain. I had not seen them for 40 years, and I remember that my mother made some oil from paulownia trees when I was young, and I also remember pastimes."

\section{Connectedness with self and neighbors}

This theme expresses the concept that participants feel that they are intimately connected to their local community and physical neighborhood through participation in the urban forest therapy program. Many participants who felt isolated found that it was important to develop social relationships.

"The forest seems to bring neighbors close to each other. It's nice to come alone here, but you will get to know your neighbors when you come with people who have not seen your face before." "When I come to the mountains alone without anyone to talk to, I have bad breath. It was so fun to play with my neighbors."

The urban forest is seen as a place where people can focus their interests and immerse themselves in enriching experiences. Some participants discussed how they came to share similar interests and connect with neighbors who liked to participate in the same type of activities through the urban forest. The following statement shows how urban forests provide motivation for people in the community to participate in the activity where no opportunities to participate had previously existed. "With people who love to walk around. I go with my (neighbor) sister to the mountain. I cannot go to areas faraway so I go to a mountain that is close to my town." "In the house, I do not have a chance to talk and I just watch TV, but I often talk about eating and living when I am in the mountain. Those who like such things come here.”

\section{Connectedness with self and nature}

The last theme identified through awareness about the urban forest and therapy program was that participants felt that 
the urban forest was a place to connect them with nature. Many participants expressed emotional feelings about fact that the urban forest provides 'fresh air and contact with nature' to them. It was also recognized as an oasis of peace to escape from the noisy 'concrete jungle.'

"When I close my eyes in the forest and try to listen to sounds, I can hear a lot of things I cannot hear in the city. The sound of the wind and the sound of birds." "As the teacher(guide for the program) says, I feel comfortable and calm compared to the other places when I listen to the sound of the forest and see the shades of green here."

In the same context as above, they discussed how nature can improve mood and enhance happiness while discussing their reasons for visiting the urban forest and participating in the therapy program. These results suggest that the characteristics of nature, which affects people's health and well-being, are among the most important factors in promoting relations with the urban forest.

"(In the program) I decided on my tree. One day when I came alone I felt the tree was talking to me. At that time, I felt comforted by the tree and I haven't felt that way from anybody or anything before, so I cried after I came back home that day." "I see a lot of trees and squirrels here and they make me remember my old days and make me feel good. Playing some childhood games such as tossing pine cones or tree sticks makes me feel like I am revisiting my past days. Now I have some fun memories."

\section{Positive and negative awareness of change}

Participants were affected by the awareness of the urban forest and the forest therapy program and realized the change in their daily lives. The theme of positive change was associated with 'Improvement of mental and emotional condition', 'Improvement in feelings of isolation and loneliness', and 'Improvement of health-related lifestyle', and the theme of the negative change was associated with 'Short-period program', 'Inconvenience of access', which were all classified into the theme that relations couldn't be maintained in terms of relationship formation.

\section{Improvement of mental and emotional condition}

This theme reflects the general belief that the urban forest provides participants with opportunities for self-reflection, serving as a place for resolving daily conflicts and feelings of resentment. The majority of the participants stated that their participation in the therapy program activities in the urban forest calms the mind and makes them feel better.

"We can all get stressed. Now I'm not stubborn and trying to win, but I'm in a bad mood. If I abandon such feelings here, I get less angry." "I sweat by exercising my body. I have fun playing childhood games, so I feel really good and I feel like I'm having a picnic."

\section{Improvement in feelings of isolation and loneliness}

Participants recognized that the activity time with their neighbors helped them reduce feelings of isolation and loneliness. Furthermore, they experienced a relaxation of the mind and body in nature through meditation, exercise and therapeutic play that enhance the five senses in nature. They also recognized that their feelings of isolation and loneliness improved as the sense of feeling distant or remote dissipated and the sense of intimacy formed while being together with their neighbors.

"The people who met here are all from the same town, so it would be nice to meet them on the street." "I liked playing games here together neighbors. I was alone all day at home. I did not get bored here because I played here all day, and I liked talking to them while having some meals together." 


\section{Improvement of health-related lifestyle}

Participants realized that the burden of taking all their meals alone and the decreased motivation resulted in dietary nutritional deficiencies, and thus the frequency and intensity of their physical activities also decreased as their physical energy decreased. However, they recognized that their physical and mental health were improved under the encouragement to acquire and practice regular and healthy lifestyle habits through the urban forest visits and the dementia prevention program activities.

"I've always done things learned here. Even when I do the dishes, I do stealthy footsteps exercise (dementia prevention exercise for the elderly). Walking on the road with soil and stones here stimulates my feet and it makes me pay attention not to fall." "At first it was hard to climb stairs. Now, everything is changed. I live a lone, so I have few meals and I didn't have enough energy. However, I eat full meals here because I do some exercise." "I don't skip meals and check what I eat everyday while reading the book (for healthy lifestyle practice) that you gave us." "I had a digestion problem. Even though I just visit the mountain once in a week, I can experience a huge effect. The nurse (who visits my home) asked me why I did not have medicine for digestion. I'm okay now without the medicine."

\section{Regret regarding the short-period program and inconvenience of access}

Participants who learned the healthy exercise methods and the healthy lifestyle practices for the prevention of dementia expressed regret about the fact that the program ended after only five sessions although they wanted to participate more because they enjoyed the program, and they expressed their desire that the program would be continuously developed.

"It's good to do it in the nearby area and exercise is fun when we do it together" "When I was in my 20s, 30s, and 40s, I felt I was healthy and I didn't need to go to the mountains. I want to go to the mountains because my body condition has deteriorated after passing middle age. This program led me here. I hope there is a program that can continues in this neighborhood."

On the other hand, there were participants who expressed their willingness to continue visiting the urban forest during their leisure time and engage in physical activities after the program was over. They learned how to spend time in the forest after participating in periodic forest experiences led by an instructor, but stated that the biggest obstacle to revisiting was transportation.

"The elderly who are not healthy cannot come here alone, so we need more of these programs."

The above results are summarized as follows. Figure 1 explored the potential psychological and social pathways in

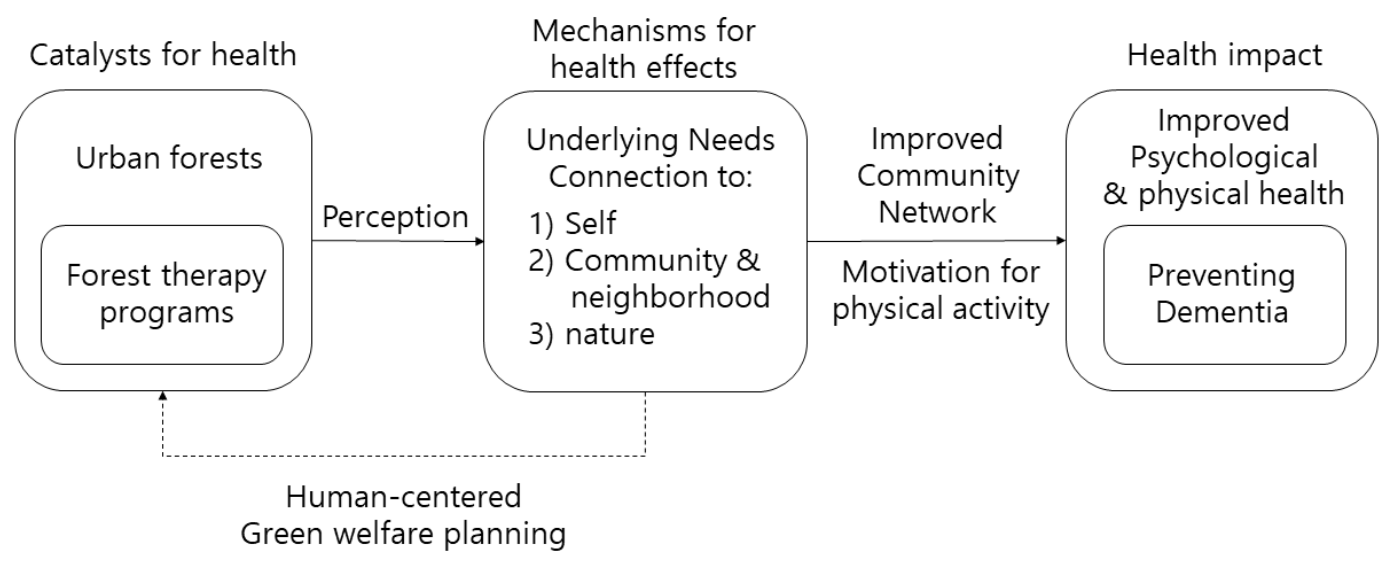

Figure 1. A human-centered green welfare framework to understand potential implications regarding the effects of urban forests and forest therapy programs on health for preventing dementia 
which the therapy program for preventing dementia using urban forests could provide opportunities for the elderly living alone on low income to form social networks and improve health and welfare in order to prevent dementia. The results also suggested a human-centered green welfare system that could form the basis for future research on preventive measures against dementia. However, it is considered that the detailed exploration of concepts and causal relations is beyond the scope of this study. Given that relationships are important to human beings as they provide beneficial effects on health and well-being (Swierad and Huang, 2018), the main implication of the results is that the expansion of green welfare, which incorporates psychological factors, is important. Specifically, the results revealed the awareness of participants regarding various relationships, and also confirmed that the relationship formation through 1) connectedness with self, 2) connectedness with neighbors, and 3) connectedness with nature, had effects on reduction in psychological and physical risk factors associated with dementia by alleviating feelings of isolation and enhancing a sense of well being, thus helping them acquire healthy lifestyle habits. This is supported by the results of advanced researches that showed the use of urban green spaces is associated with not only the basic desire for human connection with other people in terms of personal encounters, recreation, and activities, but also with a desire for connection with the larger community, nature and one's inner self (Svendsen et al., 2016).

The findings that urban forests and the therapy program helped human beings form relations and facilitate connectedness are more important when considering the increasing trend of elderly people living alone in an aging society. For example, the proportion of elderly people compared with the total population will increase to $37.4 \%$ in 2050 , and the number of elderly people with dementia is expected to increase to $15 \%$ among the elderly (MHW, 2015). Therefore, it would seem that this kind of program can contribute to the prevention of dementia and reduction of social costs by using the program as a source of social support for the elderly living alone. This suggestion is based on advanced studies that reveal that social interaction (House et al., 1988) and group activity can have a positive impact on motivation (Sonntag-Öström et al., 2015); the people within the group become more open to each other as the level of group solidarity increases (Yalom and Crouch, 1990); and processess of psychological change are stimulated through mutual understanding and interest when social relations are established in a forest environment (Rogers, 1995). As mentioned above, this effect suggests that the elderly living alone, many of who lack family and social support, have the ability to cope with their own problems, such as improving chronic diseases through healthy lifestyle habits as well as reducing depression and stress. In other words, the urban forest therapy program can be proposed as one of different policy alternatives to reduce the financial burden of the government and local governments by improving the self-health management ability of the elderly by promoting regular exercise and lifestyle changes.

\section{Conclusion}

This study examined the effects and pathways of a regular urban forest therapy program that included 'Dementia prevention exercises and forest walking', 'Five senses meditation', and 'Traditional therapeutic play' based on in-depth interviews with focus groups among the elderly living alone on low income. First, awareness about urban forests and the therapy program appeared to promote making connections with oneself, neighbors and nature. Second, this awareness developed into a willingness and effort to alleviate depression and feelings of isolation and improve health-related lifestyles. These results suggest the potential pathways for preventing dementia, in which intervention based on a naturecentered therapy program reduces psychological dementia risk factors by reducing stress and improving depression symptoms of the elderly living alone; and reduces risk factors associated with dementia such as chronic diseases by developing into a willingness and effort to improve health-related lifestyle. 
However, a limitation of this study is that it was based on a short term program composed of five sessions and outcomes and experiences could be different in relation to one-session or long-term programs. In addition, participants'personal characteristics as residents living in a specific region, the regional characteristics of their area of residence, and empirical characteristics depending on the nature of the urban forest could influence the result of the study. However, this study is considered important as a new way to refer to the use of urban forests and the development of relevant programs as health resources in the future in terms of the fact that the research was conducted by recruiting people on a voluntary basis and that the research was conducted on elderly people living alone on low income who lived in an urban area. Future research, as part of more extensive studies, will need to develop human-centered, continuous, and periodic green welfare services for the elderly living alone on low income, and it also should be expanded to include local welfare networks in order to find ways to actively combine with local issues regarding the prevention of dementia by exploring various examples of other vulnerable groups. This will provide essential information to policy makers in order that they can understand how to use urban forests as a health resource for their citizens and to support urban public health policies.

\section{References}

Barnard, N.D., A.I. Bush, A. Ceccarelli, J. Cooper, C.A. de Jager, K.I. Erickson, G. Fraser, S. Kesler, S.M. Levin, B. Lucey, M.C. Morris, and R. Squitti. 2014. Dietary and lifestyle guidelines for the prevention of Alzheimer's disease. Neurobiol. Aging 35:S74-S78. DOI:10.1016/j.neurobiolaging.2014.03.033

Bratman, G.N., G.C. Daily, B.J. Levy, and J.J. Gross. 2015. The benefits of nature experience: Improved affect and cognition. Landsc. Urban Plan. 138:41-50. DOI:10.1016/j.landurbplan.2015.02.005

Braun, V. and V. Clarke. 2006. Using thematic analysis in psychology. Qual. Res. Psychol. 3(2):77-101. DOI:10.1191/1478088706qp063oa

Deckers, K., M.P. van Boxtel, O.J. Schiepers, M. de Vugt, J.L. Muñoz Sánchez, K.J. Anstey, C. Brayne, J.F. Dartigues, K. Engedal, M. Kivipelto, K. Ritchie, J.M. Starr, K. Yaffe, K. Irving, F.R. Verhey, and S. Köhler. 2015. Target risk factors for dementia prevention: a systematic review and delphi consensus study on the evidence from observational studies. Int. J. Geriatr. Psychiatry 30(3):234-246. DOI:10.1002/gps.4245

Ennis, S.K., E.B. Larson, L. Grothaus, C.D. Helfrich, S. Balch, and E.A. Phelan. 2014. Association of living alone and hospitalization among community-dwelling elders with and without dementia. J. Gen. Intern. Med. 29(11):1451-1459. DOI:10.1007/s11606-014-2904-Z

Guba, E.G. and Y.S. Lincoln. 1989. Fourth generation evaluation. Thousand Oaks, CA: Sage Publications.

Gubrium, J.F., J.A. Holstein, A.B. Marvasti, and K.D. McKinney (Eds.). 2012. The sage handbook of interview research: the complexity of the craft. Thousand Oaks, CA: Sage Publications.

House, J.S., K.R. Landis, and D. Umberson. 1988. Social relationships and health. Science 241(4865):540-545.

Hsieh, H.F. and S.E. Shannon. 2005. Three approaches to qualitative content analysis. Qual. Health Res. 15(9):12771288.

Jia, B.B., Z.X. Yang, G.X. Mao, Y.D. Lyu, X.L. Wen, W.H. Xu, X.L. Lyu, Y.B. Cao, and G.F. Wang. 2016. Health effect of forest bathing trip on elderly patients with chronic obstructive pulmonary disease. Biomed. Environ. Sci. 29(3):212218. DOI:10.3967/bes2016.026

Kim, C.M. 2017. Development and effect analysis of nature-friendly integrated program for the elderly with mild cognitive impairment. Doctor's dissertation, Sunmoon university, Chungnam, Korea.

Kim, S.H. and E.J. Ahn. 2015. A study on developing gymnastic program for seniors with mild dementia \& walking problems : Measuring its effects. J. Sport Leis. Stud. 59(1):601-618. Retrieved from http://www.kssls.co.kr

KOSIS(Korean Statistical information service). 2016. Future population estimation. Retrieved from www.kosis.kr

Lee, K.O. 2009. The effects of the gymnastic exercise and walking program on body composition, depression and risk factors of dementia in the elderly women. Korean J. Sport Sci. 18(2):1011-1026. 
Lee, Y.J. and C.S. Shin. 2015. Effects of forest walking meditation on mood states and self-awareness in middle-aged women. J. Korean Inst. For. Recreat. 19(3):19-25.

Mama, S.K., Y. Li., K. Basen-Engquist, R.E. Lee, D. Thompson, D.W. Wetter, N.T. Nguyen, L.R. Reitzel, and L.H. McNeill. 2016. Psychosocial mechanisms linking the social environment to mental health in african americans. PLoS One 11(4):e0154035. DOI:10.1371/journal.pone.015403

Mao, G.X., Y.B. Cao, X.G. Lan, Z.H. He, Z.M. Chen, Y.Z. Wang, X.L. Hu, Y.D. Lv, G.F. Wang, and J. Yan. 2012. Therapeutic effect of forest bathing on human hypertension in the elderly. J. Cardiol. 60(6):495-502.

MHW(Ministry of Health and Welfare). 2015. The 3rd Comprehensive plan for dementia management ('16-'20). Retrieved from www.mohw.go.kr

Morse, J.M. 1994. Critical issues in qualitative research methods. Thousand Oaks, CA: Sage Publications.

Ponterotto, J.G. 2002. Qualitative research methods: The fifth force in psychology. Couns. Psychol. 30(3):394-406. DOI:10.1177/0011000002303002

Rabiee, F. 2004. Focus-group interview and data analysis. Proc. Nutr. Soc. 63(4):655-660.

Rogers, C.R. 1995. A way of being. Boston, NY: Houghton Mifflin Company.

Seo, J.O. 2007. An empirical study on reality effectiveness of improving cooperation activity of therapeutic recreation to the old dementia : Focusing on tradition game program. Master's thesis, Sangmyung University, Seoul, Korea.

Song, C., H. Ikei, and Y. Miyazaki. 2017. Sustained effects of a forest therapy program on the blood pressure of office workers. Urban For. Urban Green. 27:246-252.

Sonntag-Öström, E., T. Stenlund, M. Nordin, Y. Lundell, C. Ahlgren, A. Fjellman-Wiklund, L.S. Järvholm, and A. Dolling. 2015."Nature's effect on my mind"- Patients' qualitative experiences of a forest-based rehabilitation programme. Urban For. Urban Green. 14(3):607-614. DOI:10.1016/j.ufug.2015.06.002

Svendsen, E.S., L.K. Campbell, and H.L. McMillen. 2016. Stories, shrines, and symbols: Recognizing psycho-socialspiritual benefits of urban parks and natural areas. J. Ethnobiol. 36(4):881-907.

DOI:10.2993/0278-0771-36.4.881

Swierad, E.M and T.T.K. Huang. 2018. An exploration of psychosocial pathways of parks'effects on health: A qualtitative study. Int. J. Environ. Res. Public Health. 15(8):1693. DOI:10.3390/ijerph15081693

Tong, A., P. Sinsbury, and J. Craig. 2007. Consolidated criteria for reporting qualitative research (COREQ): a 32-item checklist for interviews and focus groups. Int. J. Qual. Health Care 19(6):349-357. DOI:10.1093/intqhc/mzm042

Vujcic, M., J. Tomicevic-Dubljevic, M. Grbic, D. Lecic-Tosevski, O. Vukovic, and O. Toskovic. 2017. Nature based solution for improving mental health and well-being in urban areas. Environ. Res. 158:385-392.

DOI:10.1016/j.envres.2017.06.03

Wimo, A., M. Guerchet, G.C. Ali, Y.T. Wu, A.M. Prina, B. Winblad, L. Jönsson, Z. Liu, and M. Prince. 2017. The worldwide costs of dementia 2015 and comparisons with 2010. Alzheimers Dement. 13(1):1-7.

DOI:10.1016/j.jalz.2016.07.15.

Yalom, I.D. and E.C. Crouch. 1990. The theory and practice of group psychotherapy. Br. J. Psychiatry. 157(2):304-306. DOI:10.1192/S0007125000062723

Yoo, S.H. 2010. A study on the environmental evaluations and suggestions of nursing homes in the aspects of environmental psychological behaviors of elderly with dementia. Master's thesis, Chung-Ang University, Seoul, Korea.

Yu, C.P., C.M. Lin, M.J. Tsai, Y.C. Tsai, and C.Y. Chen. 2017. Effects of short forest bathing program on autonomic nervous system activity and mood states in middle-aged and elderly individuals. Int. J. Environ. Res. Public Health. 14(8):897. DOI:10.3390/ijerph14080897 